\author{
Kabir-ud-Din \\ Waseefa Fatma \\ Ziya Ahmad Khan
}

\section{A $^{\mathbf{1}} \mathrm{H}$ NMR study of 1,4-bis ( $N$-hexadecyl- $\mathbf{N}, \mathbf{N}$-dimethylammonium)butane dibromide/sodium anthranilate system: spherical to rod-shaped transition}

Received: 14 June 2005

Accepted: 12 August 2005

Published online: 8 April 2006

(C) Springer-Verlag 2006

Kabir-ud-Din $(\bowtie)$.

W. Fatma - Z. A. Khan

Department of Chemistry,

Aligarh Muslim University,

Aligarh-202002,

Uttar Pradesh, India

e-mail: kabir7@rediffmail.com

\begin{abstract}
The effect of addition of sodium anthranilate to $5 \mathrm{mM}$ micellar solutions of gemini surfactant 1,4-bis ( $N$-hexadecyl- $N, N$-dimethylammonium)butane dibromide is investigated by ${ }^{1} \mathrm{H}$ NMR. The solubilization site of anthranilate anion near the micellar surface is inferred. In the micelles, the $\mathrm{An}^{-}$ions intercalate among the surfactant headgroups producing morphological changes.
\end{abstract}

\author{
Keywords ${ }^{1} \mathrm{H}$ NMR · Gemini \\ surfactants · Sodium anthranilate . \\ Micelle $\cdot$ Structural transition
}

\section{Introduction}

Systems involving surfactants constitute a field of great interest due to their wide-ranging applications in detergent and pharmaceutical industries, food technology, petroleum recovery, and so forth. Surfactants are also one of the most important constituents of cells in living systems. Therefore, physics, chemistry, biology, and technology meet at the frontier area of interdisciplinary research on association colloids formed by surfactants [1].

The presence of both non-polar (hydrophobic) and polar (hydrophilic) groups in the same molecule gives to the surfactant an amphiphilic character. These structural features determine their assembly into either micelles or other morphological forms of membranous aggregates. The micelles are generally spherical or spheroidal at concentrations slightly above the critical micelle concentration $(\mathrm{cmc})$ [2].

With increasing surfactant concentration, micelles can undergo a structural transition under appropriate conditions of salinity, temperature, or addition of some organic additives [3-9]. For most surfactants, micelles tend to grow and, in this process, change shape when an appropriate parameter is modified [2]. In most instances, this process results in the formation of elongated micelles that can become extremely long and referred to as giant, rod-like, wormlike, thread-like and polymer-like micelles [10-14].

In recent years, a new class of surfactants (known as dimeric or gemini surfactants) has generated a lot of interest in colloid chemistry $[15,16]$. These gemini surfactants possess two hydrophobic tails and two polar, or ionic, headgroups covalently attached through a linker or spacer. A great deal of variation exists in the nature of spacers, hydrophobic tails, and headgroups [16-19]. The gemini surfactants are the subject of increasing study due to their unusual solution and interfacial properties and their enhanced performance in applications, compared to analogous single-chain conventional surfactants [19]. These surfactants have been found to be superior to conventional surfactants on several counts and are said to be the "next generation of surfactants" [17]. For example, their cmc values are generally 10 to 100 times lower than the corresponding conventional surfactants [15-21].

Surfactants are generally used in the presence of additives in order to improve their properties. Thus, it is likely that dimeric surfactants in the future can be used in mixtures with various additives (e.g., conventional surfactants, organic/inorganic compounds, non-electrolytes, etc.). The existence of synergistic effects between them may 
Fig. 1 A $300-\mathrm{MHz}^{1} \mathrm{H}$ NMR spectrum of pure $5 \mathrm{mM}$ 1,4-bis $(N$-hexadecyl- $N, N$-dimethylammonium)butane dibromide (164-16) in $\mathrm{D}_{2} \mathrm{O}$

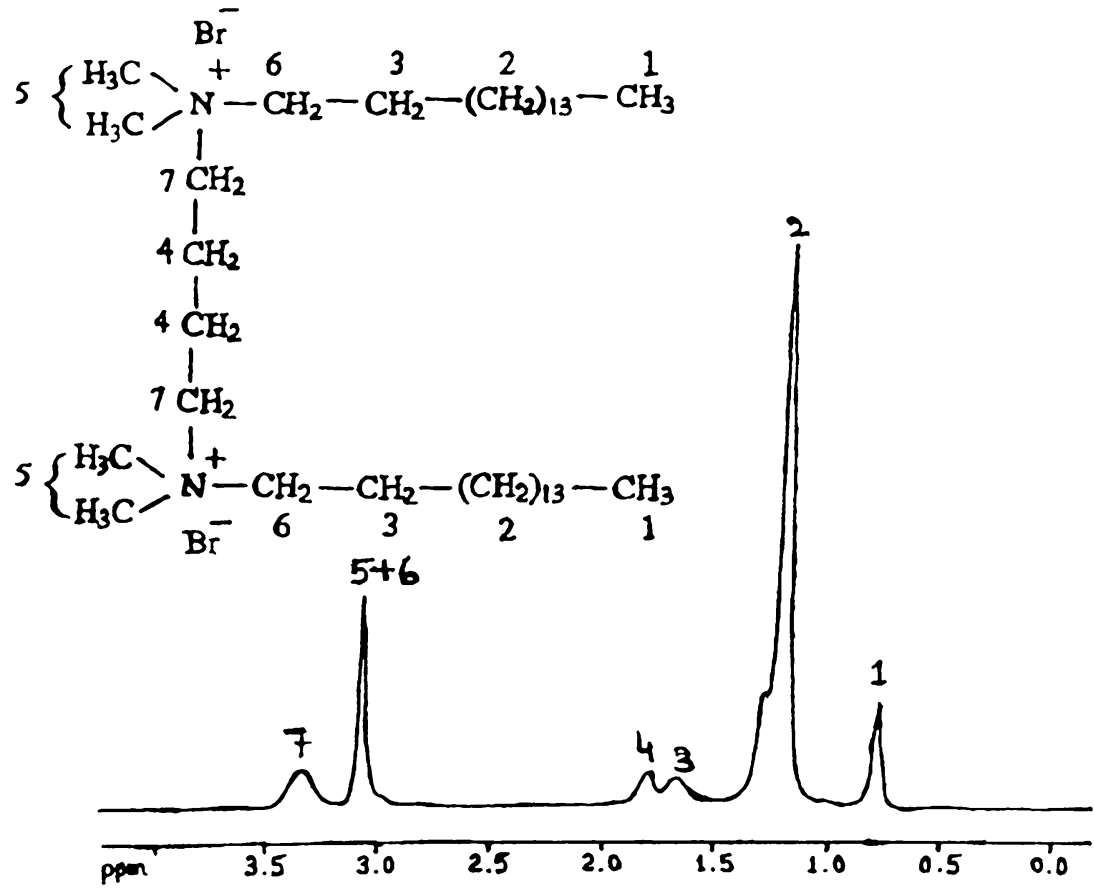

render the use of such mixtures even more attractive [2224]. It is also known that the structures of supramolecular assemblies constructed by ionic surfactants depend on counterion species; especially, the organic counterions affect the assembly structures more strongly than the inorganic counterions.

Several reports have been published on the structural aspects and aggregation behavior of dimeric surfactants [25-30]. However, literature on the micellization of gemini surfactants in the presence of different classes of additives is scarce. To our knowledge, no report has been published yet on the effect of adding salts of aromatic acids on the structure of gemini micelles. Some of these salts, depending on the nature of the groups attached to the central benzene ring, are known to produce viscoelasticity in conventional cationic surfactants [31-33]. Therefore, as a first step, we have explored the influence of the partitioning site of an aromatic salt counterion near the gemini micelle and its possible impact on overall micellar structural changes. For the purpose, we have used ${ }^{1} \mathrm{H}$ NMR to see the effect of the addition of sodium anthranilate $(\mathrm{NaAn}, \mathbf{I})$ to
$5 \mathrm{mM}$ 1,4-bis( $N$-hexadecyl- $N, N$-dimethylammonium)butane dibromide (II, a dimeric cationic surfactant, referred to as 16-4-16) solution at $25^{\circ} \mathrm{C}$.

\section{Experimental section}

Preparation of 16-4-16 gemini surfactant

The surfactant was synthesized by refluxing 1,4-dibromo butane $(\geq 98 \%$, Fluka) with $N, N$-dimethylhexadecylamine $(\geq 95 \%$, Fluka) (molar ratio $1: 2.1)$ in dry ethanol at $80^{\circ} \mathrm{C}$ for $48 \mathrm{~h}$. The solvent was removed under vacuum and the solid thus obtained was recrystallized four to five times from acetone to benzene (3:1) mixture to obtain a pure surfactant. The gemini surfactant was characterized adequately (solvent $\mathrm{CDCl}_{3}$, internal standard TMS) which gave satisfactory ${ }^{1} \mathrm{H}$ NMR and $\mathrm{C}, \mathrm{H}, \mathrm{N}$ data. The main features and peaks were similar as reported previously [34]. The cmc values determined from conductivity $\left(2.0 \times 10^{-5} \mathrm{M}\right.$, $\left.25^{\circ} \mathrm{C}\right)$ and surface tension $\left(2.63 \times 10^{-5} \mathrm{M}, 35^{\circ} \mathrm{C}\right)$ measurements
Table $1{ }^{1} \mathrm{H} \quad \mathrm{NMR}$ chemical shifts $(\delta$, ppm) of $5 \mathrm{mM} \mathrm{1,4-bis}$ ( $N$-hexadecyl- $N, N$-dimethylammonium)butane dibromide (16-4-16) surfactant with various concentrations of sodium anthranilate $(\mathrm{NaAn})$ at $25^{\circ} \mathrm{C}$

\begin{tabular}{|c|c|c|c|c|c|c|}
\hline \multirow[b]{2}{*}{$\mathrm{NaAn}(\mathrm{mM})$} & \multicolumn{6}{|c|}{ Chemical shift $(\delta, \mathrm{ppm})$} \\
\hline & 1 & 2 & 3 & 4 & $5+6$ & 7 \\
\hline 0 & 0.776 & 1.198 & 1.666 & 1.797 & 3.065 & 3.334 \\
\hline 1 & 0.915 & 1.333 & 1.726 & 1.866 & 3.174 & 3.413 \\
\hline 2 & 0.920 & 1.335 & 1.650 & 1.804 & 3.145 & 3.350 \\
\hline 3 & 0.927 & 1.340 & Disappear & Disappear & 3.123 & Disappear \\
\hline 5 & 0.928 & 1.318 & Disappear & Disappear & 3.062 & Disappear \\
\hline
\end{tabular}



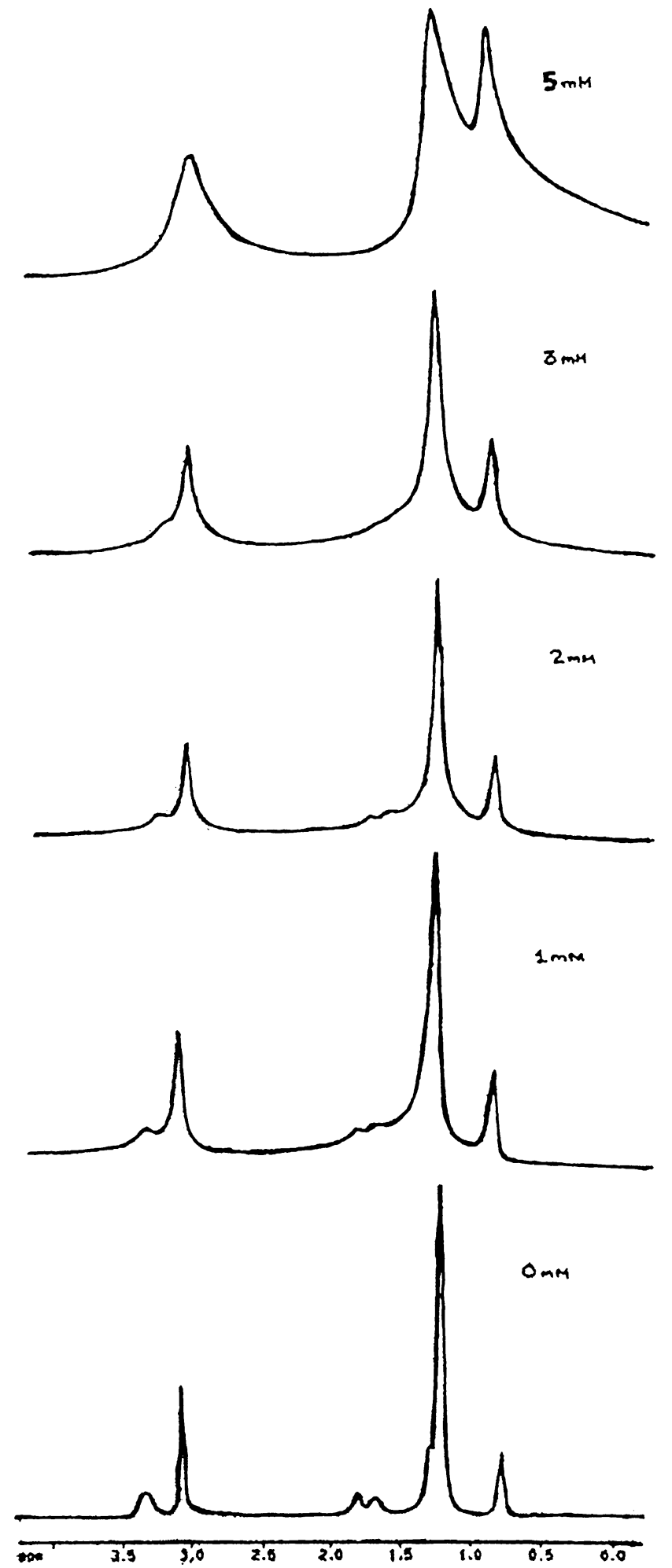

Fig. 2 A $300-\mathrm{MHz}^{1} \mathrm{H}$ NMR spectrum of $5 \mathrm{mM}$ 16-4-16 containing different concentrations of sodium anthranilate $(\mathrm{NaAn})$ in $\mathrm{D}_{2} \mathrm{O}$. For abbreviation, see Fig. 1

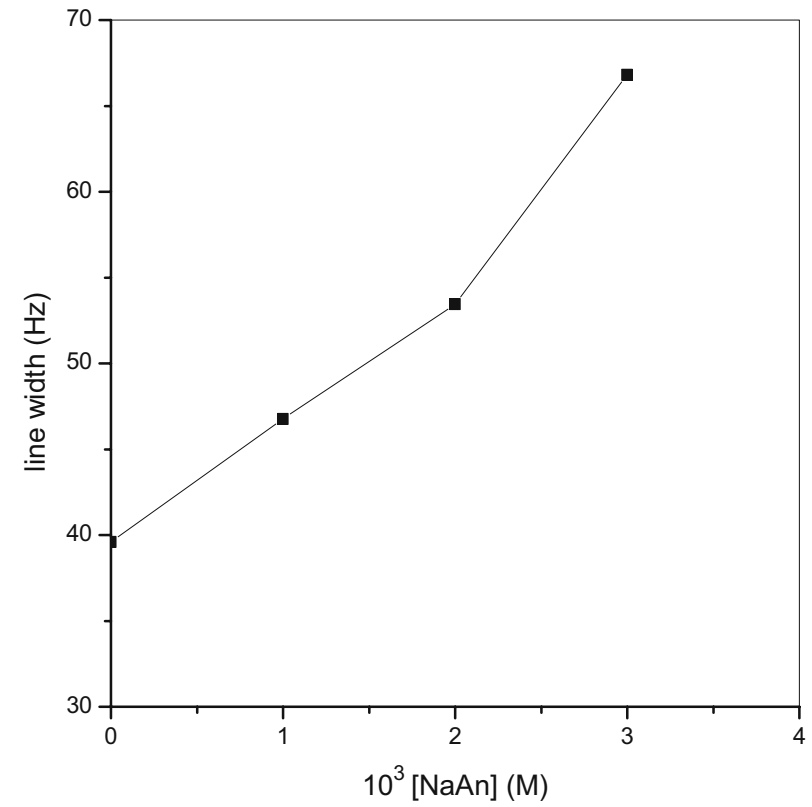

Fig. 3 Line widths of the signals from the protons of the $N$-methyl groups of 16-4-16 plotted against different concentrations of added NaAn. For abbreviation, see Figs. 1 and 2

were in close agreement with the literature value [34-36]. All solutions for the $\mathrm{cmc}$ determination were prepared in demineralized double distilled water. Also, the presence of no minimum in the surface tensions vs. [surfactant] plot was taken as additional evidence regarding the purity of 16-4-16.

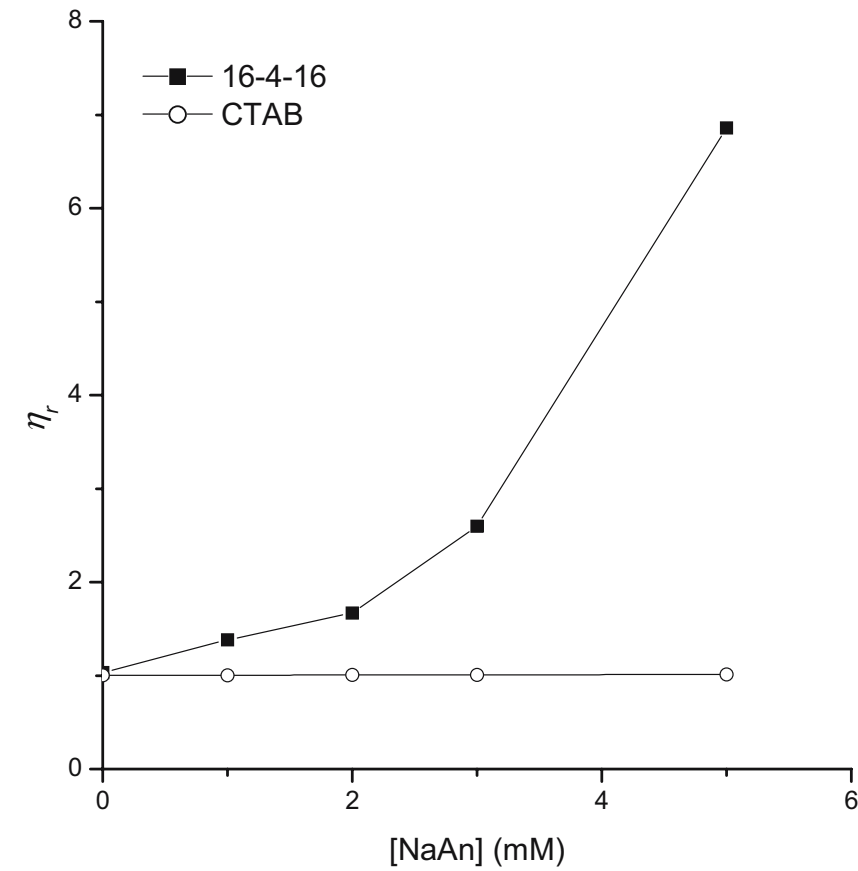

Fig. 4 Plots between relative viscosity $\left(\eta_{\mathrm{r}}\right)$ against different concentrations of added NaAn. o, cetyltrimethylammonium bromide (CTAB); $16-4-16$. For abbreviation, see Fig. 1 
Fig. 5 A $300-\mathrm{MHz}^{1} \mathrm{H}$ NMR spectrum of NaAn: a $5 \mathrm{mM}$ pure $\mathrm{NaAn}, \mathrm{b}$ with $5 \mathrm{mM} 16-4-16$ at different $\mathrm{NaAn}$ concentrations.

For abbreviation, see Figs. 1 and 2
${ }^{1} \mathrm{H}$ NMR measurements

Stock solution of $5 \mathrm{mM}$ 16-4-16 was prepared in $\mathrm{D}_{2} \mathrm{O}$ (99.9\%, Aldrich). Sample solutions of $5 \mathrm{mM} \mathrm{NaAn}(99 \%$, CPC) were prepared first by taking requisite amounts and making up the volumes by freshly prepared $5 \mathrm{mM}$ surfactant solution. To get lower concentrations, the $5-\mathrm{mM}$ samples were diluted by adding appropriate volumes of the surfactant stock solution. The sample solutions were syringed in the NMR tubes and the spectra were recorded on a Bruker Cryomagnet spectrometer working at $300 \mathrm{MHz}$.

\section{Viscosity measurements}

Viscosity measurements on 16-4-16 and cetyltrimethylammonium bromide (CTAB) $(\geq 98 \%, \mathrm{BDH})$ were carried out by an Ubbelohde viscometer thermostated at $25 \pm 0.1^{\circ} \mathrm{C}$ as done earlier [37].
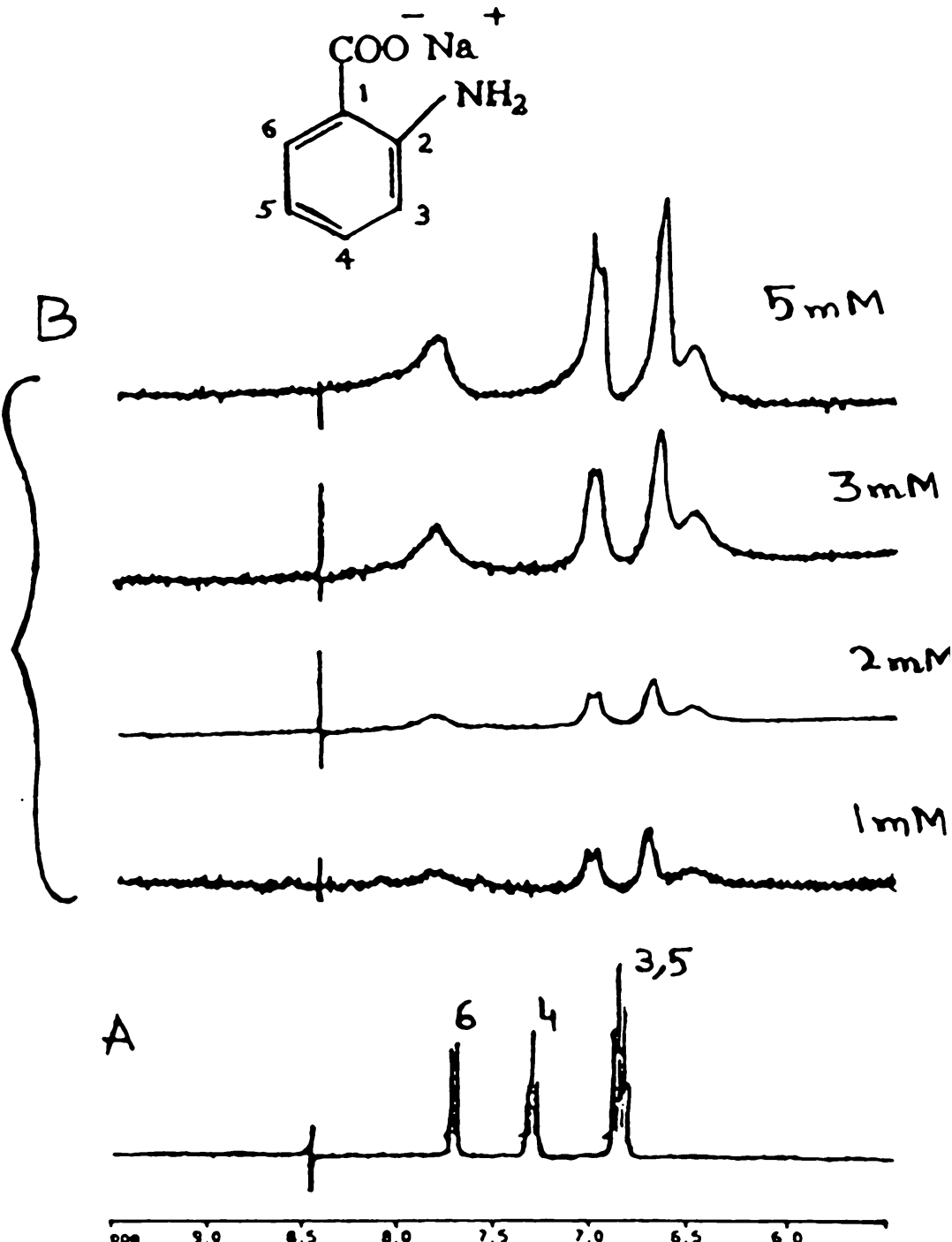

\section{Results and discussion}

Figure 1 shows the ${ }^{1} \mathrm{H}$ NMR spectra of pure $5 \mathrm{mM}$ 16-4-16 in $\mathrm{D}_{2} \mathrm{O}$. The concentration of the surfactant is much higher $(\approx 100$ times of the $\mathrm{cmc})$, thus the observed chemical shifts, $\delta$ (Table 1), can be considered those of micellized surfactant.

Table 1 shows the $\delta$ values for all surfactant resonances in the absence and presence of increasing NaAn concentration. Change in environment is experienced by the different parts of the surfactant monomers, which is indicated in the chemical shift via the shielding and deshielding effects experienced by the ${ }^{1} \mathrm{H}$ nuclei. The non-polar part of the surfactant (hydrophobic part) near the core of the micelle is highly shielded. When we move towards the headgroup, the shielding decreases. The presence of $\mathrm{N}$ atoms in the headgroup makes its adjacent protons more deshielded. On increasing the salt concentration, the peaks overlap and signals become broad. This indicates the presence of grown 
micelles in the system [38]. When the molar ratio of salt to surfactant is close to unity, signals become very broad, making evaluation difficult, as shown in Fig. 2 (5 mM salt).

The line widths at half height of the signals from the protons of the $N$-methyl groups of the surfactant are shown in Fig. 3. The data show an increase in the proton line widths with increasing [ $\mathrm{NaAn}]$. The line width values can be used to discuss structural changes in the gemini skeleton. Changes in the width can be inferred as the changes in the micellar morphology [39, 40].

Viscosity data of different concentrations of NaAn with $5 \mathrm{mM}$ of the surfactant show an increase in viscosity with increase in the [NaAn] (Fig. 4). The presence of salt ions near the polar heads of the surfactant molecules decreases the repulsion force between the headgroups. A reduction in the repulsion makes it possible for the surfactant molecules to approach each other more closely and form larger aggregates. This leads to an increase in the relative viscosity $\left(\eta_{\mathrm{r}}\right)$ indicating the formation of larger aggregates [41, 42]. Viscosity data with $5 \mathrm{mM}$ CTAB having the same concentrations of $\mathrm{NaAn}$ (as used with the gemini) are also shown in Fig. 3. The viscosity remaining almost constant for the former indicates that $\mathrm{NaAn}$ addition to 16-4-16 causes structural changes at fairly low concentration in comparison to conventional $\mathrm{CTAB}$.

This behavior of 16-4-16 is understandable due to the following. In $\mathrm{CTAB}$, the headgroups are randomly distributed on the micellar surface separating the aqueous phase and micelle core. These distances between the headgroups are determined by the opposite forces at play in micelle formation. The reported values of the surface area per headgroup at interface suggest that the distance is $\sim 0.7-$ $0.9 \mathrm{~nm}$. With gemini surfactants, the distribution distances become bimodal [19]. Indeed, the inter-headgroup distance exhibits a maximum at the equilibrium distance (as for conventional $\mathrm{CTAB}$ in the present case) and another narrow maximum at a distance corresponding to the length of the spacer. The bimodal distribution of headgroup distances and effect of the chemical link between headgroup on the packing of surfactant alkyl chain in the micellar core are expected to strongly affect the packing parameter [2] or curvature of surfactant layers, and thus to the micelle shape and the properties of the solution. The present viscosity behavior reflects the ability of 16-4-16 to give rise to worm-like micelles at fairly low $\mathrm{NaAn}$ concentration which, however, is absent with the conventional $\mathrm{CTAB}$ due to packing requirements.

The above data (Figs. 2, 3, and 4) suggest that the presence of $\mathrm{An}^{-}$ion in the micellar solution of 16-4-16 causes a change in micellar morphology. The intercalation of $\mathrm{An}^{-}$ion into the micellar surface region (due to electrostatic interactions with the oppositely charged surfactant headgroups) seems to be the prime cause of inducing such morphological changes. Additionally, $\mathrm{NaAn}(\mathbf{I})$ has a $\mathrm{NH}_{2}$ group attached to 2- position that would prefer to remain in more polar environment due to its polar nature and the geometric hindrance. Therefore, the site of solubilization of $\mathrm{An}^{-}$has direct links to the overall changes. Information regarding the environment around $\mathrm{An}^{-}$can throw some light on the partitioning of $\mathrm{An}^{-}$near micellar surface.

Figure 5 shows the ${ }^{1} \mathrm{H}$ NMR spectrum of the NaAn solution in $\mathrm{D}_{2} \mathrm{O}$. The spectrum is a first-order one and consists of three multiplets. The signals for the amino protons are not seen separately, as they are labile and thus merge with the solvent peak. The spectra of the ring protons at different concentrations of NaAn in $5 \mathrm{mM} 16-4-$ 16 are also shown (Fig. 5). It is clear that signals for the ${ }^{6} \mathrm{H}$ protons are in a polar environment and signals for ${ }^{3} \mathrm{H},{ }^{5} \mathrm{H}$ and ${ }^{4} \mathrm{H}$ are in the non-polar environment indicating that $\mathrm{An}^{-}$intercalate near the headgroups of the dimeric surfactant. At higher salt concentrations, the peaks for the $\mathrm{An}^{-}$shift up-field. This shows that at higher concentrations of $\mathrm{An}^{-}$, the effective environment experienced by ${ }^{3} \mathrm{H}$ and ${ }^{5} \mathrm{H}$ protons is different (slightly polar). This is because of the proximity of ${ }^{3} \mathrm{H}$ proton to the $-\mathrm{NH}_{2}$ group.

Hence, we conclude that the intercalation of $\mathrm{An}^{-}$ion causes a decrease in interheadgroup repulsion with a consequence of which hydrophobic interaction predominates. This is responsible for the presence of long cylindrical micelles in the solution. These cylindrical or rod-shaped micelles may produce viscoelasticity in the solution, which we are currently studying in our laboratory.

Acknowledgements WF is grateful to the Council of Science and Technology, U.P., for obtaining a Research Assistantship. Thanks are due to RSIC, Lucknow, for providing C, H, N analysis data and NMR spectra.

\section{References}

1. Evans DF, Wennerstrom H (1994) The colloidal domain where physics, chemistry, biology and technology meet. VCH, New York

2. Israelachvili JN, Mitchell DJ, Ninham BW (1976) J Chem Soc Faraday Trans $272: 1525$
3. Degiorgio V (1985) In: Degiorgio V, Corti M (eds) Physics of amphiphiles: micelles, vesicles and microemulsions. North Holland, Amsterdam, p 303

4. Shikata T, Hirata H, Kotaka T (1989) Langmuir 5:398

5. Cates ME, Candau SJ (1990) J Phys Condens Matter 2:6869
6. Kern F, Zana R, Candau SJ (1991) Langmuir 7:1344

7. Kern F, Lemarechal P, Candau SJ, Cates ME (1992) Langmuir 8:437

8. Hoffmann H, Rauscher A, Gradzielski M, Schulz SF (1992) Langmuir $8: 2140$ 
9. Toernblom M, Henriksson U, Ginley M (1994) J Phys Chem 98:7041

10. Porte G (1983) J Phys Chem 87:3541

11. Kalus J, Hoffmann, Reizlein K, Ulbricht W, Ibel K (1982) Ber Bunsenges Phys Chem 86:37

12. Lin Z, Scriven LE, Davis HT (1992) Langmuir 8:2200

13. Vinson PK, Talmon Y (1989) J Colloid Interface Sci 133:288

14. Jerke G, Pedersen JS, Egelhaaf SU, Schurtenberger P (1998) Langmuir 14:6013

15. Rosen MJ, Tracy DJ (1998) J Surfactants Deterg 1:547

16. Menger FM, Keiper JS (2000) Angew Chem Int ed Eng 39:1906

17. Rosen MJ (1993) Chemtech 23:30

18. Zana R (1998) In: Holmberg K (ed) Novel surfactants, surfactant science series, vol. 74. Dekker, New York, pp 241-277

19. Zana R (2002) Adv Colloid Interface Sci 97:205

20. Zana R (1997) In: Esumi K, Ueno M (eds) Structure-performance relationships in surfactants, chapter 6 . Dekker, New York, p 255
21. Zana R (1997) In: I Robb (ed) Specialist surfactants, chapter 4 . Chapman Hall, London, p 81

22. Camesano TA, Nagarajan R (2000) Colloids Surf 167:165

23. Bakshi MS, Kaur I, Sood R, Singh J, Singh K, Sachar S, Singh K (2004) J Colloid Interface Sci 271:227

24. Bakshi MS, Singh J, Singh K, Kaur G (2005) J Photochem Photobiol A 169:63

25. Danino D, Talmon Y, Zana R (1997) J Colloid Interface Sci 185:84

26. Rosen MJ, Zhu ZH, Gao T (1993) J Colloid Interface Sci 157:254

27. Rosen MJ, Gao T, Nakatsuji Y, Masuyama A (1994) Colloids Surf A $1: 88$

28. Menger FM, Eliseev AV (1995) Langmuir 11:1855

29. Lin L, Rosen MJ (1996) J Colloid Interface Sci 179:454

30. Zana R, Levy H, Danino D, Talmon Y, Kwetkat (1997) Langmuir 13:402

31. Gravsholt S (1976) J Colloid Interface Sci 57:575

32. Rehage H, Hoffmann H (1982) Rheol Acta 21:561
33. Aswal VK, Goyal PS, Thiyagarajan P (1998) J Phys Chem B 102:2469

34. De S, Aswal VK, Goyal PS, Bhattacharya S (1996) J Phys Chem 100:11664

35. Bunton CA, Robinson L, Schaak J, Stam MF (1971) J Org Chem 36:2346

36. Cerichelli G, Luchetti L, Mancini G, Savelli G (1997) Langmuir 15:2631

37. Kabir-ud-Din, Kumar S, Aswal VK, Goyal PS (1996) J Chem Soc Faraday Trans 92:2413

38. Anet FAL (1986) J Am Chem Soc 108:7102

39. Brinchi L, Germani R, Goracci L, Savelli G, Bunton CA (2002) Langmuir 18:7821

40. Groth C, Nyden M, Holmberg K, Kanicky JR, Shah DO (2004) J Surfactants Deterg 7:247

41. Gamboa C, Sepulveda L (1986) J Colloid Interface Sci 113:566

42. Rajagopalan V, Goyal PS, Valaulikar BS, Dasannacharya BA (1992) Physica B 180:525 